\title{
Intracranial Cavernous Hemangioma
}

National Cancer Institute

\section{Source}

National Cancer Institute. Intracranial Cavernous Hemangioma. NCI Thesaurus. Code C5432.

A cavernous hemangioma arising from the brain and meninges. 